\title{
Tax incidence under oligopoly: a comparison of policy approaches
}

\author{
Stephen F. Hamilton \\ Department of Agricultural Economics, Kansas State University, 326 Waters Hall, \\ Manhattan KS 66506-4011, USA
}

\begin{abstract}
This paper presents a methodological approach for the analysis of tax incidence that encompasses familiar forms of taxation in a general and analytically convenient model. In oligopolistic industries, the performance of a tax depends on the sensitivity of the unit tax rate to changes in industry output. Output-elastic tax schedules are less likely to be over-shifted and have superior welfare properties relative to regulatory instruments that are less responsive to the equilibrium market quantity. For revenue neutral tax reforms, the finding of Delipalla and Keen (1992) that ad valorem taxes welfare-dominate specific taxes under oligopoly is derived as a special case of this general result.
\end{abstract}

Keywords: Oligopoly; Conjectural variations; Tax incidence; Ad valorem taxation; Degressive taxation

\section{Introduction}

Despite numerous possibilities for taxation in oligopolistic industries, formal analyses of tax incidence have tended to focus on a narrow range of policy instruments. Two forms of commodity taxation frequently considered are the unit 
(or specific) tax and the sales (or ad valorem) tax. The objective of this paper is to examine oligopoly taxation through a considerably more general regulatory lens. A methodology is employed for the analysis of tax incidence that encompasses familiar forms of taxation as special cases of a general and analytically convenient model. The model allows the comparative incidence of alternative forms of taxation to be examined for a broad class of policy tools without additional calculations on the effect of individual tax reforms.

It is well known that the form of an excise tax affects market structure nonuniformly in imperfectly competitive industries. In the monopoly case, the comparative incidence of ad valorem and specific tax instruments has been thoroughly treated by Suits and Musgrave (1953). Recent research has extended the distinction to varying circumstances of homogeneous product oligopoly. In an important paper, Delipalla and Keen (1992) provide a systematic comparison of tax incidence between the two instruments and find that ad valorem taxes welfare-dominate specific taxes both in industries with a fixed number of firms and in free-entry oligopoly equilibria.

The comparative incidence of alternative tax instruments generally centers on the relative efficiency in which a tax achieves a given transfer of revenue. The conventional methodology is to consider revenue neutral tax reforms from a baseline equilibrium point. The methodological approach suggested here simplifies the distinction between equal-yield instruments by isolating the revenue transfer effect of taxation from the rotation effect of taxation on after-tax demand. This approach allows the comparative incidence of ad valorem and specific taxes to be derived as a special case of a general finding that changes in industry output and social surplus are positively-related to changes in the output elasticity of the tax schedule. For a given transfer of revenue, it is shown that relatively output-elastic tax schedules welfare-dominate regulatory controls which are less responsive to changes in the equilibrium market quantity. The aforementioned result of Delipalla and Keen (1992) is a special case of this general finding. It also follows that degressive sales taxes, which levy higher rates at higher market prices, dominate ad valorem taxes from the welfare perspective.

The methodology used here allows formal conditions to be derived in which taxation expands industry output and generates efficiency gain in noncompetitive environments. For a homogeneous product oligopoly with a fixed number of firms, both specific and ad valorem taxes are known to reduce industry output and lead to efficiency loss [see, for example, Seade (1985) and Stern (1987)]. This familiar result does not hold for the entire range of policy tools, however, as Tam (1991) demonstrates for the case of degressive taxation of a monopolized industry. In this paper, Tam's result is formally connected with the literature on oligopoly taxation

\footnotetext{
${ }^{1}$ In Tam's model, the tax is based on the price charged by a monopolist. Such a tax may be implemented equivalently as a sales tax with a variable rate, whence the price tax conceptually belongs to the class of degressive excise taxes considered by Shilling (1969).
} 
and general conditions are derived for regulatory policy to increase output and enhance economic efficiency.

The general framework employed in this paper also allows for the analysis of multiple instruments within a tax structure and thus encompasses the dual policy approaches pursued by Stern (1987) and Myles (1996). Specifically, the paper shows that output-elastic tax schedules may be constructed through the use of unit and ad valorem tax instruments, which corresponds with the dual policy considered by Myles (1996). Such a tax policy generates efficiency gain whenever the output elasticity of the tax schedule exceeds a critical value determined by various market parameters, and, when appropriately designed, eliminates the welfare loss due to imperfect competition entirely.

The remainder of the paper is structured as follows. In the next section, a framework is constructed to examine taxation under various circumstances of homogeneous product oligopoly. Section 3 develops a methodological approach for the analysis of tax incidence and derives comparative statics effects for the change in industry output, output per firm and, in the free-entry case, the equilibrium number of firms. Section 4 considers the comparative incidence of a wide range of regulatory instruments. Section 5 discusses the welfare potential of taxation in noncompetitive environments and Section 6 concludes.

\section{The oligopoly model}

Consider an oligopoly equilibrium comprised of $n$ firms which produce a homogeneous good. The output of firm $i$ is denoted by $y_{i}$ and industry output by $Y=\Sigma_{i} y_{i}$. The inverse demand function, $P(Y)$, is assumed to be negatively-sloped and twice continuously differentiable. The profit of firm $i$ is

$$
\pi_{i}=P(Y) y_{i}-c\left(y_{i}\right)
$$

where $c\left(y_{i}\right)$, the cost function of firm $i$, is henceforth assumed identical for each firm.

Strategic interaction among producers is described in the model by the conjectural variations parameter $\delta=\mathrm{d} Y / \mathrm{d} y_{i}$, where $\delta$ is treated as a constant throughout. It is well known that the conjectural variations model, in which each firm correctly predicts the effect of its actions on the industry equilibrium, reduces to special cases of perfectly competitive behavior $(\delta=0)$, Cournot-Nash behavior $(\delta=1)$, and tacit collusion $(\delta=n)$.

Confining attention to symmetric equilibria, the first- and second-order conditions for a representative firm are

$$
\pi_{y}=P+\delta y P_{Y}-c_{y}=0
$$

and 


$$
\pi_{y y}=2 \delta P_{Y}+\delta^{2} y P_{Y Y}-c_{y y}<0,
$$

respectively. First-order condition (2) may be expressed in terms of an average firm as

$$
\pi_{y}=P+\gamma Y P_{Y}-c_{y}=0,
$$

where $\gamma=\delta / n \in(0,1]$ limits attention to noncompetitive environments.

Throughout, we refer to the case in which $n$ is fixed as the Generalized Cournot model and to that in which $n$ is endogenous as the Free Entry Oligopoly model. The number of firms in the model of Free Entry Oligopoly is treated as a continuous variable following Seade (1980a), and Mankiw and Whinston (1986). Entry occurs in the industry until profits are driven to zero, whence the equilibrium number of firms, $n_{e}$, solves

$$
\pi=P\left(n y_{e}\right) y_{e}-c\left(y_{e}\right)=0,
$$

where $y_{e}$ denotes the output level of a representative firm in a symmetric oligopoly equilibrium. The equilibrium number of firms is determined simultaneously with $y_{e}$ using first-order condition (4) and entry condition (5).

The usual conditions for existence and stability of an oligopoly equilibrium are imposed. Following Dixit (1986) and Seade (1980b),

$$
k>0,
$$

where $k=1-c_{y y} / \delta P_{Y}$, and

$$
\lambda=-\left[\pi_{y y}+n(1-\gamma)\left(P_{Y}+\gamma Y P_{Y Y}\right)\right]>0 .
$$

Expression (7), a necessary condition for a maximum, requires the marginal profit of a representative firm to decrease with the sum of its own output plus the conjectured output response of rival firms.

\section{Positive effects of taxation}

Tax incidence is examined with regard to an arbitrary tax schedule that is imposed at the zero tax position. The net effect of a regulatory instrument (or combination of instruments) on the market equilibrium is modeled through the use of a shift parameter in the tax function, which allows alternative regulatory tools to be nested in a single, analytically convenient framework. The methodology

\footnotetext{
${ }^{2}$ It is assumed throughout that $n_{e}$ is unique, as is the case when fixed costs are sunk; see Vickers (1989).

${ }^{3}$ While an initial zero tax position is considered here for clarity of results, generalization is straightforward.
} 
encompasses a wide range of tax instruments as special cases involving different combinations of level effects and pivotal rotations of the tax schedule.

Consider a tax of $t(Y)$ per unit of output, which results in a profit for firm $i$ of

$$
\pi_{i}=B(Y) y_{i}-c\left(y_{i}\right)
$$

where $B(Y)=P(Y)-t(Y)$ is the net price producer $i$ receives after the tax. This formulation of the tax schedule nests several familiar forms of taxation as special cases, including the specific tax, $t=t^{S}$, the ad valorem tax, $t=t^{V} P(Y)$, and the dual policy of specific and ad valorem taxation, $t=t^{S}+t^{V} P(Y)$.

Next, let $\theta$ denote a shift parameter in the tax schedule such that $t=t(Y ; \theta)$. The shift variable is interpreted as a structural tax parameter that generalizes various policy instruments available to a regulator. Without loss of generality, a vertical upward shift (or level effect) of the tax schedule at the equilibrium point, $Y_{e}$, is described by the condition $t_{\theta}\left(Y_{e} ; \theta\right)>0$, while a clockwise (resp. counterclockwise) rotation of the tax schedule through the equilibrium point is represented by the condition $t_{Y \theta}\left(Y_{e} ; \theta\right)<0$ (resp. $>0$ ). The level effect of the tax schedule at the initial equilibrium point represents the unit value of the revenue transfer to the regulator. Thus, for the arbitrary tax structures $t^{i}$ and $t^{j}$, equal yield policy instruments may be described quite conveniently by the condition $t_{\theta}^{i}\left(Y_{e} ; \theta\right)=t_{\theta}^{j}\left(Y_{e} ; \theta\right)$.

For a given unit revenue transfer, $t=t_{\theta}\left(Y_{e} ; \theta\right)$, it is helpful to define for future reference the output elasticity of the tax schedule as $\Psi=-t_{Y \theta} Y / t_{\theta}$. The output elasticity of the tax schedule measures the sensitivity of the tax rate to changes in the equilibrium level of output. A policy of specific taxation involves $t_{\theta}=t^{S}$ and $t_{Y \theta}=0$, which implies $\Psi=0$, while a policy of ad valorem taxation involves $t_{\theta}=P t^{V}$ and $t_{Y \theta}=P_{Y} t^{V}$, whence $\Psi=\eta$ where $\eta=-P_{Y} Y / P$ is the output elasticity of demand.

Proposition 1. In the Generalized Cournot model, taxation affects industry output as

$$
\frac{\mathrm{d} Y}{\mathrm{~d} \theta}=\frac{-n t_{\theta}(1-\gamma \Psi)}{\lambda}
$$

In the model of Free Entry Oligopoly, taxation affects industry output as

$$
\frac{\mathrm{d} Y}{\mathrm{~d} \theta}=\frac{t_{\theta}\left(\pi_{y y}-n \gamma^{2} P_{Y}(\Psi-E)\right)}{P_{Y} \pi_{y y}},
$$

\footnotetext{
${ }^{4}$ The reader should note that while equal-yield policy instruments, as described above, are not fully revenue neutral, tax structures that meet this definition involve an identical 'first round' effect on tax revenue. This definition of equal-yield tax structures extends in straightforward fashion the concept of 'matched pairs' of taxes introduced by Suits and Musgrave (1953) and provides the conceptual underpinning for tax reforms of the type considered by Delipalla and Keen (1992).
} 
where

$$
E=-P_{Y Y} Y / P_{Y}
$$

Proof. The first part (8) is derived by applying the implicit function theorem to (4), once (1) is replaced by $\left(1^{\prime}\right)$, then aggregating across $n$ firms. Again replacing (1) with $\left(1^{\prime}\right)$, the second part (9) is derived by perturbing (4) and (5), with application of the envelope theorem to (5). The resulting system of equations is

$$
\left[\begin{array}{cc}
-\lambda & \left(P_{Y}+\gamma Y P_{Y Y}\right) y \\
(1-\gamma) P_{y} Y & P_{Y}\left(y^{2}\right)
\end{array}\right]\left[\begin{array}{l}
\mathrm{d} y \\
\mathrm{~d} n
\end{array}\right]=\left[\begin{array}{c}
t_{\theta}+\gamma Y t_{Y \theta} \\
y t_{\theta}
\end{array}\right] \mathrm{d} \theta .
$$

Denoting the coefficient matrix in (11) by $\Sigma$, its determinant is

$$
\operatorname{Det}(\Sigma)=P_{Y} y^{2} \pi_{y y} .
$$

The effect of a change in tax structure on the output of a representative firm and on the equilibrium number of firms is

$$
\frac{\mathrm{d} y}{\mathrm{~d} \theta}=\frac{-\gamma t_{\theta}(\Psi-E)}{\pi_{y y}},
$$

and

$$
\frac{\mathrm{d} n}{\mathrm{~d} \theta}=\frac{t_{\theta}\left(\pi_{y y}-n \gamma(1-\gamma) P_{Y}(\Psi-E)\right)}{y P_{Y} \pi_{y y}},
$$

respectively. The effect of a change in tax structure on industry output is calculated from (13) and (14) as $\mathrm{d} Y / \mathrm{d} \theta=n(\mathrm{~d} y / \mathrm{d} \theta)+y(\mathrm{~d} n / \mathrm{d} \theta)$, which yields (9).

The output effect in (8) depends on the level effect of the tax, $t_{\theta}$, the conjectural variations parameter, and the output elasticity of the tax schedule, $\Psi$. The output effect in (9) depends on these same parameters and on the value of $E$, which is the elasticity of the slope of inverse demand. Taxation increases industry output in (8) and (9) when the tax schedule is sufficiently output-elastic.

For special cases of specific taxation and ad valorem taxation, a positive tax rate reduces industry output, as noted elsewhere in the literature. In the Generalized Cournot model, the denominator of (8) is positive by condition (7). For the case of specific taxation, the numerator of $(8)$ becomes $-n t^{S}<0$, while, for the case of $a d$ valorem taxation, the numerator of (8) becomes $-n\left(P+\gamma Y P_{Y}\right) t^{V}<0$ by (4). In the Free Entry Oligopoly model, specific taxation affects industry output in (9) as

$$
\frac{\mathrm{d} Y}{\mathrm{~d} \theta}=\frac{n \gamma(1+k) t^{S}}{\pi_{y y}}<0,
$$

where the inequality holds by stability condition (6) and the second-order condition (3). Hence a specific tax leads to a reduction in industry output as in 
Besley (1989) and Delipalla and Keen (1992). For the case of ad valorem taxation, the output effect is

$$
\frac{\mathrm{d} Y}{\mathrm{~d} \theta}=\frac{n \gamma\left[P k+\left(P+\gamma Y P_{Y}\right)\right] t^{V}}{\pi_{y y}}<0,
$$

where the inequality holds by conditions (4), (5), and (6).

Proposition 2. A tax is over-shifted into price in the Generalized Cournot model iff

$$
\Psi<[E-k]
$$

A tax is over-shifted into price in the model of Free Entry Oligopoly iff

$$
\Psi<E \text {. }
$$

Proof. Taxation is over-shifted when the change in the consumer price exceeds the unit value of the tax, $\mathrm{d} P / \mathrm{d} \theta>t_{\theta}$. Recognizing that the change in the consumer price is $\mathrm{d} P / \mathrm{d} \theta=P_{Y}(\mathrm{~d} Y / \mathrm{d} \theta)$, it follows that over-shifting of a tax into price occurs in the Generalized Cournot model iff

$$
n P_{Y} t_{\theta}(1-\gamma \Psi)+\lambda t_{\theta}<0
$$

Expression (17) reduces to

$$
n \gamma P_{Y} t_{\theta}(\Psi+k-E)>0 .
$$

Noting that $t_{\theta}>0$ under the tax yields (15).

In the Free Entry Oligopoly model, over-shifting of a tax into price occurs iff

$$
t_{\theta}\left(\pi_{y y}-n \gamma^{2} P_{Y}(\Psi-E)\right)-t_{\theta} \pi_{y y}<0 .
$$

Collection of terms completes the proof.

Corollary. The over-shifting of a tax, $t^{i}$, is a necessary, but not a sufficient condition, for the over-shifting of an equal-yield tax, $t^{j}, \forall t^{j} \neq t^{i}$ such that $\Psi^{i}>\Psi^{j}$.

Proposition 2 and the corollary encompass familiar results on the incidence of oligopoly taxation. For example, a specific tax is over-shifted in a Generalized Cournot model with linear costs iff $E>1$ as in Seade (1985) and Stern (1987), while, in the model of Free Entry Oligopoly, a unit tax is over-shifted iff $E>0$ as derived by Besley (1989). The corollary also generalizes the finding of Delipalla and Keen (1992) that over-shifting of specific taxes is a necessary, but not a sufficient condition, for over-shifting of ad valorem taxes. It also follows that $a d$ valorem taxes are shifted into price to a greater degree than are taxes with a 
relatively stronger rotation effect, such as the degressive taxes discussed by Shilling (1969) and Tam (1991).

\section{Tax incidence and social welfare}

We next consider the welfare implications of tax incidence. Social surplus is denoted as a function of the structural tax parameter, $\theta$, by

$$
W(\theta)=\int_{0}^{Y(\theta)} P(z) d z-n c(y(\theta))
$$

in the Generalized Cournot model and by

$$
W(\theta)=\int_{0}^{Y(\theta)} P(z) d z-n(\theta) c(y(\theta))
$$

in the Free Entry Oligopoly model. The tax revenue collected by the regulator is a pure transfer that is unrelated to welfare measures (18) and (19). ${ }^{6}$ From the zero tax position, we have:

Proposition 3. In the Generalized Cournot model, taxation affects social surplus as

$$
\frac{\mathrm{d} W}{\mathrm{~d} \theta}=\frac{-n t_{\theta}\left(P-c_{y}\right)(1-\gamma \Psi)}{\lambda} .
$$

In the model of Free Entry Oligopoly, taxation affects social surplus as

$$
\frac{\mathrm{d} W}{\mathrm{~d} \theta}=\frac{-\gamma n t_{\theta}\left(P-c_{y}\right)(\Psi-E)}{\pi_{y y}} .
$$

Proof. Differentiating (18) for the welfare effect of taxation,

$$
\frac{\mathrm{d} W}{\mathrm{~d} \theta}=\left(P-c_{y}\right)\left(\frac{\mathrm{d} Y}{\mathrm{~d} \theta}\right)
$$

in the Generalized Cournot model. Expression (22), combined with (8) yields (20).

\footnotetext{
${ }^{5}$ One functional form of a degressive tax is the sales tax $t=t(Y) P(Y)$, where $t^{\prime}(Y)<0$. Such a tax varies inversely with output level and corresponds with the price tax considered by Tam when $t(Y)=t_{p} / Y$.

${ }^{6}$ The model is developed in partial equilibrium and does not consider distortionary effects of taxation in other economic sectors or administrative losses of tax revenue.
} 
In the Free Entry Oligopoly model, the effect of taxation on social surplus is found by differentiating (19), which yields

$$
\frac{\mathrm{d} W}{\mathrm{~d} \theta}=P\left(\frac{\mathrm{d} Y}{\mathrm{~d} \theta}\right)-n c_{y}\left(\frac{\mathrm{d} y}{\mathrm{~d} \theta}\right)-c\left(\frac{\mathrm{d} n}{\mathrm{~d} \theta}\right) .
$$

Substitution of (9), (13) and (14), making use of (5), completes the proof.

In (20) and (21), taxation leads to efficiency gain when the tax schedule is sufficiently output-elastic, as $\lambda>0$ by stability condition (7) and $\pi_{y y}<0$ by the second-order condition (3).

Corollary. A tax schedule, $t^{i}$, welfare-dominates an equal-yield tax schedule, $t^{j}$, $\forall t^{j} \neq t^{i}$ such that $\Psi^{i}>\Psi^{j}$.

The corollary to Proposition 3 provides an analytically convenient benchmark for assessing the comparative incidence of alternative tax instruments under oligopoly. A tax policy $i$ welfare-dominates an equal-yield tax policy $j$ if and only if tax policy $i$ involves a larger clockwise rotation of the tax schedule at the equilibrium point. It follows readily that ad valorem taxation dominates specific taxation from the welfare perspective, as in Delipalla and Keen (1992). The result is also useful for assessing the welfare properties of other, less familiar tax forms. Consider, for example, the comparative incidence of ad valorem and degressive taxation, where the degressive sales tax, $t=t^{D}(Y) P(Y)$, satisfies $t_{Y}^{D}(Y)<0$. From the zero tax position, an ad valorem tax satisfies $\Psi=\eta$, while a degressive sales tax, $t_{\theta}=t^{D} P$ and $t_{Y \theta}=t^{D} P_{Y}+t_{Y}^{D} P$, satisfies $\Psi=\tau+\eta$, where $\tau=-t_{Y}^{D} Y / t^{D}$ is the output elasticity of the degressive tax rate. Given the larger rotation effect induced by the latter tax, it follows that degressive taxation dominates ad valorem taxation from the welfare perspective.

Tax schedules that are sufficiently output-elastic increase industry output and enhance economic efficiency. For example, if a degressive sales tax is imposed in a oligopoly with a fixed number of firms, industry output and social surplus increase by Propositions 1 and 3 if $\tau+\eta>1 / \gamma$, or, using first-order condition (4), if

$$
\gamma P \tau>c_{y}
$$

In expression (23), a degressive sales tax expands industry output and increases social surplus when the conjectured value of a decrease in the sales tax from a marginal expansion of output exceeds its marginal cost.

Alternatively, it is possible to construct an output-elastic tax schedule by combining multiple tax instruments, as in the dual policy of ad valorem and specific taxation considered by Stern (1987) and Myles (1996). A convenient policy implication emerges in the comparison of an ad valorem tax structure, 
$t^{j}=P t^{V_{j}}$, with a tax schedule that combines ad valorem taxation and unit subsidization, $t^{i}=P t^{V_{i}}-t^{S}$. At the zero tax position, equal yield tax structures $\left(t_{\theta}^{i}=t_{\theta}^{j}=t_{\theta}\right)$ must satisfy $t_{\theta}=P t^{V_{i}}-t^{s}=P t^{V_{j}}$, whence it must be the case that $t^{V_{i}}>t^{V_{j}}$ for any non-zero subsidy rate, $t^{S}$. Clearly, then, $\Psi^{i}=P_{Y} t^{V_{i}} / t_{\theta}>P_{Y} t^{V_{j}} / t_{\theta}=$ $\Psi^{j}$ and it follows directly that a dual policy of ad valorem taxation and unit subsidization welfare dominates the use of ad valorem taxation alone.

Propositions 1 and 3 are summarized as follows.

Proposition 4. If $\Psi>($ resp. $<) \gamma^{-1}$ in the Generalized Cournot model, then

1. industry output rises (resp. falls) with taxation;

2. social surplus increases (resp. decreases) with taxation.

If $\Psi>($ resp. $<) E$ in the Free Entry Oligopoly model, then

1. output per firm increases (resp. decreases) with taxation;

2. taxation is shifted by less (resp. more) than 100 percent into price;

3. social surplus increases (resp. decreases) with taxation.

Proposition 4 extends several familiar results in the literature on oligopoly taxation. In the Generalized Cournot model, both industry output and social surplus decline under unit taxation as in Seade (1985) and Stern (1987). Under ad valorem taxation, social surplus also declines as $n<\gamma^{-1}$ holds by first-order condition (4), although the effect is less pronounced than in the case of specific taxation. In the Free Entry Oligopoly model, Proposition 4 reduces to Proposition 1 of Besley (1989) for the case of a specific tax, whereas part 3 is as in Delipalla and Keen (1992) for the case of an ad valorem tax.

\section{Tax structure and economic efficiency}

This section describes the corrective potential of a wide class of alternative tax structures. In particular, attention is confined to regulatory structures that lead to the social optimum. Thus, the objective is contextually similar to that of Stern (1987) and Myles (1996), although a single generalized tax structure is employed rather than one of dual policy. For expositional purposes, attention is limited here to the Free Entry Oligopoly model in order to parallel the development of Myles (1996) for dual policy in the Generalized Cournot case.

Consider a representative firm in an oligopoly industry that faces an equilibrium 
tax rate of $t=t(Y)$ for each unit of output produced. After-tax profits of the firm are given by

$$
\pi=P(Y) y-c(y)-t(Y) y,
$$

whence the equilibrium in the Free Entry Oligopoly model is completely characterized by

$$
P(n y)=c_{y}(y)-\delta y P_{Y}(n y)+t(n y)+\delta y t_{Y}(n y),
$$

and

$$
y P(n y)=c(y)+y t(n y) .
$$

The socially optimal $y, n$ pair satisfies the first-order conditions associated with the welfare expression (19),

$$
P(n y)=c_{y}(y),
$$

and

$$
y P(n y)=c(y) .
$$

The following Proposition extends the result of Myles (1996).

Proposition 5. In the Free Entry Oligopoly model, a tax schedule always exists that eliminates the welfare loss due to imperfect competition entirely.

Proof. It is necessary to show that if $y^{*}$ and $n^{*}$ satisfy (27) and (28), they will also satisfy (25) and (26). First notice that if the revenue transfer under a tax schedule is nonzero at a social optimum, then it is obvious that (26) cannot be satisfied by $y^{*}, n^{*}$. To complete the proof, it is necessary to demonstrate that if the revenue transfer at the social optimum is zero, then (25) will be satisfied by $y^{*}$, $n^{*}$.

Suppose that $y^{*}$ and $n^{*}$ satisfy (27) and (28) and let the tax schedule be represented by the conditions $t\left(n^{*} y^{*}\right)=0$ and $t y\left(n^{*} y^{*}\right)=P y\left(n^{*} y^{*}\right)$. Then, it follows immediately from (27) that $y^{*}, n^{*}$ also satisfy (25).

This simple result confirms intuition and assures that a tax schedule can restore full optimality in noncompetitive environments. The optimal tax schedule pivots after-tax demand horizontally at the socially optimal price, thereby forcing imperfect competitors to act as price-takers in the market. ${ }^{7}$ One means of

\footnotetext{
${ }^{7}$ This result is consistent with Myles (1996), who finds in the Generalized Cournot case that a dual policy that combines an ad valorem tax of $100 \%$ and a specific subsidy equal to marginal cost eliminates the welfare loss due to imperfect competition.
} 
implementing such a tax is a degressive tax of the form $t=P(Y)-P\left(n^{*} y^{*}\right)$. In the face of such a tax, a representative firm makes profits of

$$
\pi=P(Y) y-c(y)-\left(P(Y)-P\left(n^{*} y^{*}\right)\right) y
$$

and behaves according to the first-order condition

$$
\pi_{y}=P+\gamma Y P_{Y}-c_{y}+P\left(n * y^{*}\right)-P-\gamma Y P_{Y}=0 .
$$

Expression (29) reduces to $P\left(n^{*} y^{*}\right)-c_{y}(y)=0$, whence $y=y^{*}, P(n y)=P\left(n^{*} y^{*}\right)$ by (26), and the social optimum is achieved with a single policy instrument. This result is somewhat contrary to the conventional intuition that dual policy instruments are required to correct two market distortions. A single tax of a sufficiently degressive nature corrects two market distortions with one instrument, which underscores the importance of the shape of the tax schedule in determining equilibrium outcomes under oligopoly.

The optimal tax schedule may also be implemented using a dual policy approach. To the extent that regulatory tools have differential impacts on the level and slope of the after-tax demand function, it is possible to achieve a social optimum through various combinations of tax instruments. In the context of the present model, an optimal dual pricing policy employs one instrument to rotate demand horizontally and another to adjust the level effect to the social price. This simple, parenthetical observation provides sharp relief to the comparative incidence of individual policy instruments, as unit taxes, ad valorem taxes, and degressive taxes involve respectively larger rotations of after-tax demand for a given level effect.

\section{Concluding comments}

This paper employs a shift parameter in a generalized tax schedule to analyze the incidence of taxation under oligopoly. The methodological approach encompasses a wide range of regulatory instruments and allows for convenient policy comparison of alternative tax structures. The paper demonstrates that the degree of tax shifting in an oligopoly is inversely related to the output elasticity of the tax schedule. An output-elastic tax schedule is associated with greater industry output, increased output per firm, and, in the case of free entry oligopoly, a larger reduction in industry fixed costs relative to a tax schedule that is less responsive to the equilibrium level of output. The welfare consequences of taxation under oligopoly thus improve with revenue neutral reforms to relatively output-elastic tax schedules, whence degressive taxes welfare-dominate ad valorem taxes vis á vis the welfare superiority of ad valorem over specific taxation.

The paper also presents formal conditions in which taxation leads to increased output and efficiency gain. The results confirm those of other studies that unipartite policies of specific or ad valorem taxation unambiguously lead to 
efficiency loss in oligopolistic industries with a fixed number of firms. Conversely, degressive taxes and dual policies of ad valorem and specific taxation generate efficiency gain whenever the output elasticity of the tax schedule exceeds a critical value determined by various market parameters.

The methodology employed in this paper may be used for the further examination of tax incidence under oligopoly. The model allows the effects of taxation to be conveniently analyzed for a broad class of oligopoly equilibria and for a wide range of regulatory instruments. Future implementation of this methodological approach may provide greater latitude for the evaluation of alternative tax structures and permit the corrective potential of various fiscal instruments to be more comprehensively illuminated than present space allows.

\section{References}

Besley, T.J., 1989. Commodity taxation and imperfect competition: A note on the effects of entry. Journal of Public Economics 40 (3), 359-367.

Delipalla, S., Keen, M., 1992. The comparison between ad valorem and specific taxation under imperfect competition. Journal of Public Economics 49 (3), 351-367.

Dixit, A., 1986. Comparative statics for oligopoly. International Economic Review 27 (1), 107-122.

Mankiw, G., Whinston, M., 1986. Free entry and social efficiency. Rand Journal of Economics 17 (1), 48-58.

Myles, G.D., 1996. Imperfect competition and the optimal combination of ad valorem and specific taxation. International Tax and Public Finance 3 (1), 29-44.

Seade, J.E., 1980. On the effects of entry. Econometrica 48 (2), 479-489.

Seade, J.E., 1980. The stability of Cournot revisited. Journal of Economic Theory 23 (1), 15-27.

Seade, J.E., 1985. Profitable cost increases and the shifting of taxation: Equilibrium responses of markets in oligopoly. University of Warwick Discussion paper no. 260.

Shilling, N., 1969. Excise Taxation of Monopoly. Columbia University Press, New York.

Stern, N.H., 1987. The effects of taxation, price control and government contracts in oligopoly and monopolistic competition. Journal of Public Economics 32 (2), 133-158.

Suits, D.B., Musgrave, R.A., 1953. Ad valorem and unit taxes compared. Quarterly Journal of Economics 67 (4), 598-604.

Tam, M.-Y.S., 1991. Tax on price: A new commodity tax structure for efficiency. Public Finance 46 (1), 123-133.

Vickers, J.S., 1989. The nature of costs and the number of firms at Cournot equilibrium. International Journal of Industrial Organization 7 (4), 503-509. 